$\xi=$ 离

\title{
Report on the experiences of fourth year nursing students registered for the degree of bachelor of nursing science at the university of Namibia, regarding rural placement in 2014
}

\author{
Joan. M. Kloppers *, L. N. Nelumbu, M.B. Tibinyane \\ Faculty of Health Sciences: School of Nursing; University of Namibia \\ *Corresponding authorE-mail: jkloppers@unam.na
}

\begin{abstract}
The School of Nursing and Public Health sends every year the final year nursing degree students to rural placements. Students are send to the different clinics and hospitals in regions namely; - Khomas, Otjozondjupa, Kharas, Erongo, Omaheke, Kavango East and West, Otjikoto and Zambezi region. The students were placed from the 2nd June to 4th June 2014. Rural placement is organized because of complaints received from the public sector. It was uttered that newly qualified professional nurses after having obtained their degrees, lack the skills to operate independently.

Aim: The aim of rural placement for fourth year nursing students is to gain knowledge and to develop the necessary skills to practice independently under the supervision of a qualified and experience registered nurse.

Method: No actual research was conducted. The answers were collected from the fourth year nursing students' reports.

Results: The findings from the report of the fourth year nursing students were positive and negative. The findings were divided in themes and sub themes by using Tech's method. The positive responses were:

Management of administrative aspects. Platform to work independently; Students learn to apply their critical thinking.

Practice how to manage a health facility: Learn more on integrated management of neonatal and childhood diseases

Management of hypertension, asthma and other emergency cases.

Students Experience the difference between rural and urban. Distances were very far; roads are difficult to travel; There is not always a doctor and you had to make own decisions for the patient.

Prepare students to become responsible and accountable professional nurses.

Work under supervision of the registered nurse.

Negative responses were: Staff shortage; no delegation at some places; poor communication; language barriers; far distances.

Conclusion: Although there were some hiccups the students were very grateful for the exposure to the rural placement. Students have learnt a lot of activities they were previously not fully confident of.
\end{abstract}

Keywords: Rural Placement; Fourth Year Degree Students; Experiences.

\section{Introduction}

\subsection{Overview and rationale}

After independence Namibia inherited a health service delivery structure that was segregated along racial lines, based on curative health service only. The system of service delivery was two tier for the district and central hospital. This resulted in unequal allocation of resources. The second tier health system was also poorly funded by the National Policy on Community Based Health Care, (2014). Namibia adopted the Primary Health Care (PHC) concept in 1990. In line with its objective of health for all Namibians, resources were shifted to the disadvantaged regions. Primary Health care is defined as the "essential health care based on practical, scientifically sound and socially acceptable methods and technology, made universally accessible to individuals and families in the community. It is through their full participation and at a cost that the community and the country can afford to maintain at every stage of their development in the spirit of self-reliance and self-determination" World Health Organization, (1978). This means that PHC is an approach to health beyond the traditional health care system that focuses on health equity-producing social policy Starfield, (2009) and Public Health Agency of Canada, (2011). PHC includes all areas that plays a role in health, such as access to health services, environment and lifestyle Marcos, (2004).

Due to lack of practical experience, students were placed in rural settings to gain more knowledge and to work independently.

Students were placed in rural clinics during May and 26 June 2014. These placements were in various regions throughout Namibia. The regions were Khomas region, Karas region, Oshakati, Zambezi (which was previously Caprivi), Erongo and Omaheke region.

The reasons for placement in the regions were;-

- To gain more practical experience

- To work independently

- To apply their critical thinking skills. 
- $\quad$ To practice how to manage a Health facility.

- To gain more knowledge in integrated management of childhood diseases

- To experience the difference between urban and rural practice.

- To prepare students to become responsible and accountable professional nurses.

- To work under the supervision of registered nurses.

Supplementary to rural placement of students, considerable preparation prior to placement was required. A committee was formed with the following responsibilities:

Convener:

The role of the convener was to call weekly or impromptu meetings with different committees, in order to determine progress regarding allocated responsibilities.

Administrator

The responsibility of this person was to draft permission letters to the various regional directors for placement of students at the specified health facilities and to request accommodation and meals for the students during placement. The administrator was also responsible for the allocation of students to the different regions. Students were preferably allocated to their regions of origin/ birth.

Accommodation:

This committee was responsible for arranging of accommodation for students in various regions, especially where no accommodation was available at the said health facilities.

Transport:

This committee was responsible for arranging transport to and from the various regions. All students departed on the same day to the various regions.

Finance

The finance committee had the responsibility of compiling and distributing a list with relevant details of all the fourth year students (Windhoek and Northern Campus). This list contained the following details: student name; student number and bank details. The banking details were required by the finance office in order to issue money to the students for subsistence during their placement.

\subsection{Problem statement}

Students registered for the degree of Bachelor of Nursing Science (clinical) at the School of Nursing and Public Health at the University of Namibia were placed in the rural regions for clinical practice experience in their fourth year of study. There is no evidence of reports on the performance of the students themselves or by the supervisors as well as from the lecturers.

Verbal complaints were raised from the public sector in the regions that after completion of the four year degree program the newly graduated, lacked practical skills to operate independently.

\subsection{The purpose of the rural placement}

The purpose of rural placement was for the final year nursing student to gain experience, knowledge and skills to practice independently under supervision of a registered nurse.

\subsection{Objective of the report}

The objectives of the Report include the following:

- To explore and describe the experiences of fourth year nursing degree students during rural placements

\subsection{Operational definitions}

Rural placement: Rural areas can also be described as remote areas that are 50 to a 100 kilometers from a regional town

Fourth year degree student: These are final year students doing their bachelor of nursing science degree (clinical) at the University of Namibia.

Experiences
Is the knowledge and skills that students gained while they were allocated in the rural areas Hornby, (2010).

\section{Research methodology}

\subsection{Research design}

The research design selected for this study was qualitative, exploratory and descriptive design

\subsection{Population}

The population was the 4th year degree students doing their bachelor of nursing science degree (clinical) at the University of Namibia who went on rural placement on the $2^{\text {nd }}$ June till $4^{\text {th }}$ July 2014. Students were requested to submit a written report in their groups on their experiences on rural placement.

Sample and sampling

All the $4^{\text {th }}$ years who participated according to the regions in which they worked.

Data Collection and analysis.

Data collected from a written reports and was done unstructured. Analyzed by employed Tesch's approach of open coding to develop an organized system of data and to form themes and sub themes (Tesch, 1995)

\section{Descriptive research and literature control}

\subsection{Introduction}

Results and literature Control

- Themes were derived from the experiences of student nurses during their rural placement. Some gained positive and others negative practical experiences.

Table 3.1: Identified Themes and Sub-Themes on the Experiences of Fourth Year Degree Student

\begin{tabular}{|c|c|}
\hline Main Themes & Sub- Themes \\
\hline $\begin{array}{l}\text { 1. Management and } \\
\text { Administration }\end{array}$ & 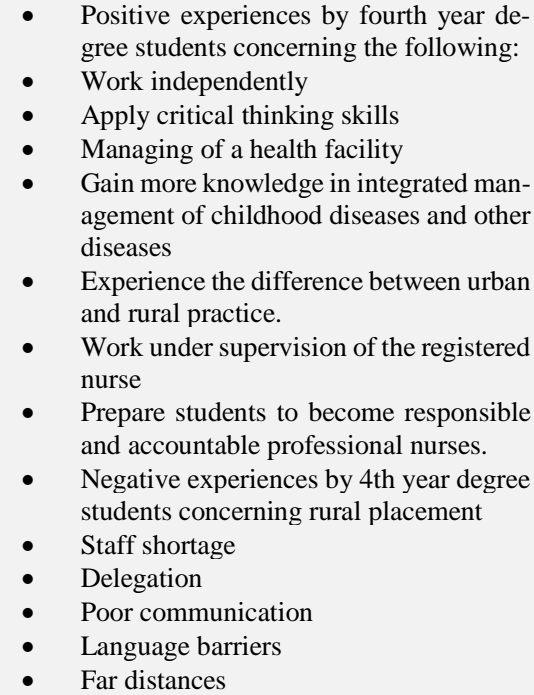 \\
\hline
\end{tabular}

\subsection{Main themes and sub-themes}

Discussion of the main themes and sub-themes

\subsubsection{Main theme: 1 management and administration aspects}

To manage a health facility correctly students need to gain knowledge and skills to manage and to administer. During the four year training of students they need to learn more of management aspects and be given the opportunity to manage a health facility. 3.2.1.1Sub themes of Management and administration aspects 
The following are the sub- themes: work independently, apply critical thinking skills and how to manage a health facility and to gain more knowledge on integrated management of childhood diseases. The $4^{\text {th }}$ year students experience the difference between urban and rural practice that contribute to prepare them to become responsible and accountable professional nurses.

\section{Work independently}

According to Collins English Dictionary, (2014) independently means not to be influenced or controlled by others in matters of opinion, conduct, etc.; thinking or acting for oneself: It also means not influenced by the thought or action of others: not relying on another or others for aid or support. Capable of acting for oneself or on one's own.

Students were exposed when they are placed in rural settings. They also receive individual attention that they do not receive in the urban areas due to the big number of students. They are also allowed to make their own decisions concerning problems they experienced during rural placement.

The following statements were made by student nurses about work independently.

"Rural placement was a good experience."

"We got a change to familiarized our self with medication that usually prescribed by doctors or stay in the pharmacy at Katutura health center."

"Platform to be independent and accountable of our own action." Concluding remarks on working independently

\section{Apply their critical thinking skills}

According to Beyer (1995) Critical thinking means making clear, reasoned judgments. While in the process of critical thinking, your thoughts should be reasoned and well thought out/judged urban settings students depend on the lecturer and registered nurses in clinical areas for decision making and do not get the opportunity to apply their critical thinking.

The following was the remarks of the students on critical thinking. "Critical thinking as we were face with different scenarios."

"We learnt a lot. We learned about treatment that is prescribed at the clinic setting."

\section{Practice on how to manage a health facility}

\section{Gain more knowledge in integrated manage- ment of childhood diseases and other dis-} eases

Integrated Management of Childhood diseases was adopted from World Health Organization (WHO) to look at the child more holistic and not to concentrate only on the complaint.

The World Health Organization (WHO) and UNICEF developed Integrated Management of Childhood Illness (IMCI) as a strategy to reduce diseases amongst the under $5 \mathrm{~s}$. GlaxoSmithKline (GSK) has been involved with IMCI since 1996 when it initiated a unique partnership with the South African Ministry of Health as well as Namibia. Since then, GSK has entered into public-private partnership agreements with WHO, UNICEF, National Ministries of Health and/or NGOs for the implementation of the IMCI strategy or components thereof in Ethiopia, Namibia, Nigeria, Ghana and Kenya.

IMCI aims to reduce morbidity and mortality due to the major killer diseases for children under five: malaria, diarrhea, malnutrition, measles, pneumonia, HIV/AIDS and neonatal causes. The strategy includes three main components: 1) improving the case management skills of health workers; 2) strengthening the health system; and 3) improving key household and community practices that
Under the Government Republic of Namibia-UNICEF Young Children Health Care and Development Program, GlaxoSmithKline has been supporting the implementation of all 3 components of IMCI (mainly c-IMCI) in six districts (Windhoek, Omaruru, Mariental, Opuwo, Katima Mulilo and Engela) - with infant and under-five mortality rates of 52 and 71 per 1000 live births respectively.

The following is the remarks of the students.

"This placement was the best everything in our practical placement."

"We have learnt a lot unlike in Windhoek because we are a lot and attention is limit"

"Learnt more on hypertension and how to immediately care for asthma attacks".

"We learned more in detail on IMCI."

"Very nice clinic to learn, many cases observed."

\section{Experience the difference between urban and rural practice}

Student nurses in the urban settings are always under supervision of the lecturer as well as the registered nurse in clinical practice. In rural settings there are usually staff shortage and students are left independent to function under supervision of the nurse in charge. The following statements from fourth year student nurses

"It was rural area we learned a lot unlike being in town where you are limited".

"In the rural area you are the nurse doctor and pharmacist".

"You learnt to do a lot of things like diagnosing and prescribing which you don't do in towns so you are exposed to the real world gain more experience."

"We learnt a lot during the placement like treatment of certain diseases illnesses. It makes all of us competent and confident in what we are doing."

"In conclusion, the placement taught us a lot of activities that we were not confident in them. It gave us knowledge." "Thank you for the opportunity!!!"

According to Van Hofwegen, Kirkham Harwood, (2005) research has shown that students who have a positive learning experience in the rural setting are more likely to work in the rural settings after graduation. Rural areas include also some negative learning experiences isolation, limit access to health care resource and long distances between service and provider.

\section{Prepare students to become responsible and accountable professional nurses}

Whether you are a nurse or a student the principle of accountability and delegation is important for the health worker and your patient supervision account. The nurse in charge usually delegate aspects of care to colleagues with skills and knowledge and competence. Students all have the duty of care and are legal liability and ensure that they perform competently with regard to patients (RCN, 2008). According to Bampton, in order to meet challenges of caring it is clear that the foundation of nursing should be strengthened by training and education during clinical placement. The core responsibilities in the clinical settings include assessment of patients the execution of delegated interventions with their scope of practice, record keeping and reporting to the registered nurse

(Nursing Board of Namibia, 1998)

The following statements from students.

"We learned about emergencies handling."

"We gained knowledge on how to run a clinic control medications and how to be a good clinic supervisor."

"All in all the placement was nice, we were independently and gave us more confidence as future registered nurses. If anything taught us to work hard under pressure and with limited resources, it was this placement."

In order for anyone to be accountable they must have the ability and accept responsibility and have the authority within job description, 
policies and protocols to perform the task. Delegation is the process by which the delegator allocate clinical and non-clinical treatment to a competent person. The principles of delegation is as follows: must be done to the best interest of the patient. The student need to receive training and patients should expect the same standard of care (RCN, 2006)

\section{Work under the supervision of regis- tered nurses}

Students had the following to say

"All in all the placement was nice, we were independently and gave us more confidence as future registered nurses."

"We got proper orientation to various departments and hospital During the morning assembly allocate time to every one of us to say our experience."

"Every one of us got an opportunity to present a health education topic to the whole clinic."

"We worked well with them as a team and we have learned a lot from them. They used to give us demonstrations and signed our books."

"Nurses are willing to teach and work with students although the clinic situation is not allowing it due to a lot of patients."

"Very nice clinic to learn, many cases observed."

"Log books were signed accordingly"

\section{Negative challenges encountered}

\section{Management/ administration activities}

Fourth year students had the following to say.

'The third week of our rural placement there was poor cooperation between us and the clinic staff.

"Poor management between district management team member and clinic staff."

"The staff members lack of teamwork and had a lot of personnel issues they brought to work.

The clinic lack organization."

"When we arrived in one of the regions, the management at the district office was not informed about our arrival they didn't know they are expecting students from UNAM.'

\section{Staff shortage}

According to Brookes, (2013) the World Health Organization (WHO) stated that more health care workers needs to be trained very fast. The World Health Organization (WHO) released a new report, November 11 that estimates that the world will be short 12.9 million healthcare workers by 2035 . Today, that figure stands at 7.2 million. The shortage of healthcare workers can be due to retiring or leaving the profession coupled with not enough young people entering the profession.

The report further predicted that in developed countries, $40 \%$ of nurses will leave health employment in the next decade. "With demanding work and relatively low pay, the reality is that many young health workers receive too few incentives to stay in the profession. The report predicts that the biggest shortages in health providers will be in parts of Asia and in sub-Saharan Africa, where just 168 medical schools exist. Of the 47 countries in sub-Saharan Africa, 11 have no medical schools and 24 have only a single such school, the report notes the report encourages all countries to address the healthcare worker shortage and provides a detailed list of recommendations to strengthen human resources for health in the setting of universal health coverage.

Nursing students indicated:
"It was a different experience. We did not get what we expected. It was not how we thought about it. Staff works with difficulty. Students concerns are not considered. Not enough staff/ shortage of staff."

"We were only two students and the clinic is ever full patients. Yet there were not enough staff members therefore we did not get enough attention from sisters and time for our books."

"Staff absent if they saw students and we had very little time to attend to our books as we were covering staff shortage most of the time."

"The sisters and all the staff members were willing to help although procrastinating a lot when it came to singing or teaching us. Part of the reason could be because of the work load and that the clinic was under staffed and was to be open seven days with $07 \mathrm{~h} 00$ to $19 \mathrm{~h} 00$ shifts."

The shortage of staff influence the services in health care facilities that will not be provided. The publication stated that $90 \%$ of all maternal deaths and $80 \%$ of all still births occur in 58 countries, largely because countries lack trained midwives. Also, of the 6.6 million under-five year olds who died in 2012, most deaths were treatable and preventable diseases. Again, more health workers would prevent most of those unnecessary young deaths (Thomas, 2013). Healthcare workforce researchers and analysts have been arguing for the past couple of years over whether a dire physician shortage will materialize as predicted. The status of nursing supply and demand remains uncertain. For years, experts have warned about looming nursing shortages. However, an article in the New England Journal of Medicine last year stated that these shortages have failed to materialize. At the same time, the article said future demand itage of nurse practitioners ( Salke, 2014)

\section{No delegation}

Delegation can be defined as the assignment of responsibility or authority to another person (normally from a manager to a subordinate) to carry out specific activities. It is one of the core concepts of management leadership. The person who delegated the work remains accountable for the outcome of the delegated work. Delegation empowers a subordinate to make decisions, i.e. it is a shift of decision-making authority from one organizational level to a lower one. Delegation, if properly done, is not abandonment. In general, delegation is good and can save money and time, help in building skills, and motivate people.

Student nurses stated the following:

"We did not learn anything at this health facility. We were isolated from other fourth years us from Oshakati campus. We were not satisfied with their delegation of this facility because they delegate us to work in Family planning; Growth monitoring and expanded programme of immunizations for the two first consecutive weeks and the last week of our placement they don't allow to treat patients according to the prescription we are taught at school."

"Another unpleasant and disturbing thing was that there is no delegation done at the clinic and staff decides where they want to work and other areas will be neglected and only some nurses will be working to cover all places."

Poor delegation, on the other hand, might cause frustration and confusion to all the involved parties (12 Rules of Delegation, 2009). Some agents however do not favor a delegation and consider the power of making a decision rather burdensome (Angst, Lukas and Karol J. Borowiecki 2013).

\section{Poor communication}

Communication is the act or process of using words, sounds, signs, or behaviors to express or exchange information or to express your ideas, thoughts, feelings, etc., to someone else a message that is given to someone : a letter, telephone call, etc. Communication is a two-way process of common understanding, in which participants not only information, news, ideas and feelings but also create and share meaning. In general, communication is a means of connecting 
people or places. In nursing, it is the key function of management-an organization cannot operate without communication between levels, departments and employees (Business Dictionary, 2014).

Student nurses stated the following:

"Poor communication within the district. Poor handling of matters of concern between health workers and the clinic."

\section{Language barrier}

Language can be an obstacle for the communication between health worker and the client. Namibia is a vast country with 11 ethnical groups speaking their own languages. If you can't communicate with the client/patient and cannot provide health education. Most clients usually brings and interpreter or with the help of another health worker client/patient can be help. Since Independence in 1990 the official language for Namibia is English although most of the elderly can communicate in Afrikaans. A study conducted in Namibia on the effects of language barriers on treatment of HIV found that patient provider language barriers were not associated with a change in likelihood of patient adherence and were associated with low provider and patient positive score $a=0.05$.level though they were not significant. Furthermore the presence of a translator increases the length of consultation but does not affect adherence or positive affect the provider (Moore, 2013).

"Language barrier as most of the people speaks Afrikaans and Khoekhoe."

\section{Far distances}

Some of the requirements of Primary Health Care is that medical services must be available and accessibil whenever people need them. Health services need to be 5 to $10 \mathrm{~km}$ in reach for a person as well as convenient for a person (Salama, 2014).

Participants had the following to say.

"There is just a distance in case of referrals to the hospitals which is $130 \mathrm{~km}$ and for severe cases and those in labor will be a treat. A doctor and pharmacist are needed in the health facility.'

A study conducted on rural remote health in Canada found that the long driving distances and severe weather as well as poor road construction can influence the client's health (Killan, Carter, 2010).

The consequences of far distances can also imply that clients can die in case of emergencies on their way to the health facility.

\section{Recommendation}

- Rural placement time is too short and if it is possible we are kindly requesting for UNAM to extent the rural placement duration at least two months

- Rural placement be introduced from third year of study then it will be more meaningful and helpful for learning.

- The clinics that received for the first time students for rural placement requested at least to be informed beforehand what the students' needs were, so they are prepared for them.

- Supervisors and lectures should follow up the students when they are at the rural placement.

\section{References}

[1] Angst, Lukas and Karol J. Borowiecki (2013) Delegation and Motivation, Theory and Decision, forthcoming.

[2] Bampton, E.L. (2011). Guidelines for clinical nursing education of the pupil enrolled nurse and midwife in Namibia. University of Namibia, Namibia.

[3] Beyer, B. K. (1995). Critical thinking. Bloomington, IN: Phi Delta Kappa Educational Foundation.

[4] Bussinessdictionary.com http://www.businessdictionary.com/definition/communication. html\#ixz z3J2OGogwY

[5] Brookes, M. (2013). Worsening global health worker Medscape multispecialty shortage WHO Collins English Dictionary, (2014).
Definition independent.www.collinsdictionary.com $>$ English dictionary.

[6] Hornby A.S. (2010). Oxford advanced learners Dictionary of Current English Oxford UniversityPress http://www.businessdictionary.com/definition/communication.html\#ixzz3J2OGogwY.

[7] Killam L.A., Carter, L.M. (2010). Challenges of the student nurses on clinical placement in the rural setting: A review of Literature http//www rrh. org,au.

[8] Marcos, Cueto (2004). "The ORIGINS of Primary Health Care and SELECTIVE Primary Health Care.". Am J Public Health. 22 94: 1864-1874.

[9] Moore, Q. (2013). The effects of language barriers on treatment of HIV https/digital. LibWashington edu/research works handle/1773 24265

[10] Nursing Board of Namibia, (1998). Minimum requirements for the education and guide concerning the teaching of enrolled pupils in the program leading to enrolement as a nurse midwife. Namibia.

[11] Public Health Agency of Canada. About Primary Health Care. Accessed 12 July 2011.

[12] RCN (Royal College of Nursing): (2008). Health care assistants and assistant Practioners Delegation and Accountability.

[13] RCN (Royal College of Nursing) et al: (2006). A guide for registered $P R$ actioners and support Workers.

[14] Salka, S. (2014). Healthcare Staff Shortages? Industry Research.

[15] Salama, R. (2014) Community medicine. Suez Canal University Egypt.

[16] Starfield, Barbara. "Politics, primary healthcare and health." J Epidemiol Community Health 2011; 65:653-655 https://doi.org/10.1136/jech.2009.102780.

[17] Tesch, R. (1995). Qualitative research: analysis types and software tools. New York Falmer.

[18] Thomas, G. (2013). Worsening global health worker Medscape Report warning Recife Brazil.

[19] Van Hofwegen, L. Kirkham, S. Harwood, C. (2005). The strength of rural nursing: Implication for under graduate nursing education. International journal of nursing education Scholarship 2 (1): 1-13 https://doi.org/10.2202/1548-923X.1142.

[20] International World Health Organization. Declaration of Alma-Ata. Adopted at the International Conference on Primary Health Care, Alma-Ata, USSR, 6-12 September 1978.

[21] World Health organization (2013). A Universal Truth: No Health without a Workforce 12 Rules of Delegation - Retrieved December 17, 2009http://pmhut.com. 